ARAGÃO, F.A.S.; GIORDANO, L.B.; MELO, P.C.T; BOITEUX, L.S. Desempenho de híbridos experimentais de tomateiro para processamento industrial nas condições edafo-climáticas do cerrado brasileiro. Horticultura Brasileira, Brasília, v.22, n.3, p. 529-533, jul-set 2004.

\title{
Desempenho de híbridos experimentais de tomateiro para processamento industrial nas condições edafo-climáticas do cerrado brasileiro
}

\author{
Fernando A.S. Aragão ${ }^{1}$; Leonardo de B. Giordano ${ }^{1,3}$; Paulo C.T. Melo ${ }^{2}$; Leonardo S. Boiteux ${ }^{1,3}$ \\ ${ }^{1}$ Embrapa Hortaliças, C. Postal 218, 70359-970 Brasília-DF; ${ }^{2}$ ESALQ, C. Postal 09, 13418-900, Piracicaba-SP; ${ }^{3}$ Bolsista de Produtivida- \\ de em Pesquisa do CNPq
}

\section{RESUMO}

Foram avaliadas as características de produção e qualidade industrial de 26 híbridos experimentais de tomateiro. Os híbridos comerciais 'Hypeel 108' e 'RTP 1095' foram utilizados como testemunhas. O ensaio foi conduzido de julho a novembro de 2001, na fazenda Agriter (Coopercentro) no município de Cristalina-GO, empregando um sistema de irrigação via pivô central. O delineamento experimental foi o de blocos casualizados completos com três repetições. As parcelas foram compostas de duas linhas com 30 plantas cada, em um espaçamento de $0,5 \mathrm{~m}$ entre fileiras e $0,25 \mathrm{~m}$ entre plantas. Foram avaliadas as características: produção de fruto maduro (FM), produção de fruto verde $(\mathrm{FV})$, produção total $(\mathrm{PT})$, uniformidade de maturação (UM), sólidos solúveis [(grau brix $\left({ }^{\circ} \mathrm{B}\right)$ ], rendimento de pasta (RP), firmeza do fruto (FF) e cor do fruto (CF). O híbrido 'TEH-22' obteve a maior produção de frutos maduros (109,04 t/ha), o 'TEH-26' a melhor uniformidade de maturação (94,56\%), o 'TEH-06' a maior produtividade total (124,31 t/ha), o híbrido comercial 'Hypeel 108 ' o maior valor de ${ }^{\circ} \mathrm{B}$ e o híbrido 'TEH01 ' o melhor rendimento de pasta (17,40 t/ha). Observaram-se diferenças estatisticamente significativas para todas as características avaliadas, exceto para firmeza de fruto. O contraste "híbridos experimentais" $x$ "híbridos comerciais" foi significativo para FM, FV, $\mathrm{PT},{ }^{\circ} \mathrm{B}$ e RP e não significativo para UM, CF e FF. Os híbridos 'TEH01', 'TEH-03', 'TEH-14', 'TEH-21', 'TEH-22', 'TEH-23', 'TEH25' e 'TEH-26' foram selecionados simultaneamente por três índices de seleção: Clássico, Multiplicativo e distância GenótipoIdeótipo. As linhagens 'CNPH 1299', 'CNPH 1306', 'CNPH 1346' e 'CNPH 1278' se destacaram por estarem presentes, como parentais, nas combinações que deram origem aos híbridos selecionados. Os grupos dos híbridos obtidos a partir de cruzamentos com a linhagem 'CNPH 1299' e da linhagem 'CNPH 1346' foram os que apresentaram melhor desempenho no experimento de acordo com a informação obtida via contrastes ortogonais. Os resultados obtidos indicam que com um pequeno esforço nas áreas de pesquisa e desenvolvimento, será possível, a médio prazo, a liberação de híbridos nacionais capazes de competir com os melhores híbridos importados.

Palavras-chave: Lycopersicon esculentum, processamento industrial, parâmetros genéticos.

\begin{abstract}
Field performance of processing tomato hybrids in the “Cerrado" region of Brazil

Genetic parameters for yield and processing characteristics were estimated using 26 experimental processing tomato hybrids in an experiment conducted in Cristalina, Goiás State, Brazil. The commercial hybrids 'Hypell-108' and 'RTP1095' were used as standards. The experimental design was a randomized complete block with three replications. Each plot consisted of two rows (30 plants each) spaced $0.50 \mathrm{~m}$ apart with a within row distance of $0.25 \mathrm{~m}$. The following parameters were evaluated: mature fruit yield (FM), green fruit yield (FV), total fruit yield (PT), uniformity of fruit ripening $(\mathrm{UM}=(\mathrm{FM} / \mathrm{PT}) \times 100)$, soluble solids [brix $\left.\left({ }^{\circ} \mathrm{B}\right)\right]$, paste yield $(\mathrm{RP})$, fruit color $(\mathrm{CF})$ and fruit firmness $(\mathrm{FF})$. Significant differences were found among the 26 experimental hybrids for FM, FV, PT, UM, ${ }^{\circ} \mathrm{B}$, $\mathrm{RP}$ and CF. Experimental hybrids (as a group) were superior to the commercial hybrids for FM, FV, PT and RP. The commercial hybrids (as a group) had superior performance only for ${ }^{\circ} \mathrm{B}$, as compared to experimental hybrids. However, six experimental hybrids had ${ }^{\circ} \mathrm{B}$ values similar to that of 'Hypell-108'. A negative genotypic correlation (-0.40) was observed between FV and FM. A negative $(-0.27)$ genotypic correlation was observed between $\mathrm{CF}$ and ${ }^{\circ} \mathrm{B}$. Both associations are undesirable from the breeding for processing industry standpoint. A multivariate analysis indicated FM, UM, ${ }^{\circ} \mathrm{B}$ and $\mathrm{CF}$ as being the traits with highest relevance to discriminate hybrid performance. A multi-trait selection indicated eight experimental hybrids with superior performance in this assay. The top one (' $\mathrm{CNPH}$ 1346 ' $x$ 'CNPH 1272') had $40 \%$ and $58 \%$ higher paste yield production as compared to 'Hypeel-108' and 'RPT1095', respectively. The groups of experimental hybrids with the inbred lines 'CNPH 1299' or 'CNPH 1346' as parental had the best performances in this assessment. These $F_{1}$ hybrids could be recommended for commercial production in Central Brazil.
\end{abstract}

Keywords: Lycopersicon esculentum, industrial processing, genetic parameters.

(Recebido para publicação em 18 de novembro de 2003 e aceito em 18 de maio de 2004)

$\mathrm{O}$ segmento que envolve o processamento de tomate é um dos mais importantes da indústria agro-alimentar brasileira. $\mathrm{O}$ valor global do mercado brasileiro de derivados de tomate no final da década de 90 foi avaliado em 500 milhões de dólares (Melo e Vilela, 2004). A área plantada em 2001 foi de aproximadamente 15.000 ha sen- do que a produção alcançou na safra de 1999 a marca recorde de 1,3 milhão de toneladas (Silva e Giordano, 2000). A produtividade vem aumentando ao longo dos anos, passando de $35 \mathrm{t} / \mathrm{ha}$ em 1990 para 68,9 t/ha em 2001, representando um aumento de $96,8 \%$. Este notável aumento da produtividade pode ser explicado, em parte, pela incorporação das áreas sob cerrado. Atualmente, Goiás e Minas Gerais respondem por cerca de $90 \%$ da produção nacional de tomate para processamento. As condições edafo-climáticas para o cultivo do tomateiro nesta região são mais adequadas do que as existentes nas antigas zonas tradicionais de cultivo do Nordeste e do estado de São Paulo. As condições 
de cultivo no cerrado favorecem o uso mais racional de defensivos e a mecanização mais intensa, facilitando operações tais como transplantio e colheita.

Nas últimas décadas, foi também observada uma progressiva substituição de cultivares de polinização aberta por híbridos $\mathrm{F}_{1}$. Em meados da década passada, a área ocupada por híbridos era de apenas $12 \%$ e em 2001 foi superior a 95\% (Barbosa, 1997; Melo e Vilela, 2004). Em 2003, cultivou-se um total de 20.000 ha de tomateiro destinado ao processamento industrial, sendo $51 \%$ desta área foi ocupada por híbridos de uma única companhia de semente. $\mathrm{O}$ preço médio pago pelas companhias processadoras foi de US\$ 3,5 por 1000 sementes. Esses híbridos foram desenvolvidos no exterior e suas sementes são importadas. $\mathrm{O}$ aumento de produtividade e melhoria da qualidade da matéria-prima resultante da utilização de híbridos importados representa um desafio à indústria brasileira de sementes no sentido de desenvolver programas de melhoramento visando a obtenção de linhagens e combinações híbridas adaptadas às condições edafo-climáticas do cerrado. O presente trabalho teve como objetivo avaliar o desempenho de híbridos experimentais de tomateiro para processamento industrial do programa de melhoramento genético da Embrapa Hortaliças nas condições de cerrado brasileiro.

\section{MATERIAL E MÉTODOS}

O ensaio foi conduzido de julho a novembro de 2001, na fazenda Agriter (Coopercentro) no município de Cristalina-GO, sendo utilizado para irrigação o sistema de pivô central. Utilizaram-se 26 híbridos experimentais $\mathrm{F}_{1}$ resultantes da combinação de diversas linhagens do programa de melhoramento de tomate para processamento da Embrapa Hortaliças. Os híbridos comerciais 'Hypeel 108' e 'RTP 1095' foram as testemunhas. $\mathrm{O}$ delineamento experimental utilizado foi o de blocos casualizados completos com três repetições. As parcelas foram compostas de duas linhas com trinta plantas cada, em um espaçamento de $0,5 \mathrm{~m}$ entre fileiras e 0,25 m entre plantas. Foram avaliadas as características: produção de frutos maduros (FM), produção de frutos verdes (FV), produção total (PT), uniformidade de maturação (UM), teor de sólidos solúveis totais [grau brix $\left({ }^{\circ} \mathrm{B}\right)$ ], rendimento de pasta (RP), cor do fruto (CF) e firmeza do fruto (FF).

O caráter PT ( $\mathrm{t} / \mathrm{ha}$ ) foi calculado pela soma da produção de frutos maduros com a de frutos verdes $(\mathrm{FM}+\mathrm{FV})$. A variável uniformidade de maturação indica o percentual de frutos maduros em relação à produção total [UM $(\%)=$ (FM/PT) x 100]. O teor de sólidos solúveis totais foi medido com um refratômetro (Atago ${ }^{\circledR}$, modelo ATC-1). A variável rendimento de pasta (padronizada para $28^{\circ} \mathrm{B}$ ) foi obtida pela seguinte expressão: $\mathrm{RP}=\left(0,94 \times \mathrm{FM} \times{ }^{\circ} \mathrm{B}\right) /$ 28. O caráter cor do fruto foi avaliado por meio de nota em uma escala de 1-5 onde 1 = fruto descolorido e 5 = fruto vermelho intenso. A firmeza também foi utilizada uma escala subjetiva de notas que variou de $1=$ fruto muito mole a 5 $=$ fruto muito firme.

Dois modelos de contrastes ortogonais foram propostos. No primeiro, comparou-se o grupo de híbridos de um determinado genitor contra os demais híbridos do ensaio. Neste caso, o critério de seleção do genitor foi o número de vezes em que o mesmo figurou como parental dentre os híbridos selecionados como melhores. Em um outro contraste, comparou-se cada híbrido comercial com o grupo formado por todos os híbridos experimentais (Gomes, 2000). A identificação dos híbridos de melhor desempenho no experimento foi realizada por meio de três índices de seleção: Clássico (Smith, 1936; Hazel, 1943), Multiplicativo (Subandi et al., 1973) e distância Genótipo-Ideótipo (Cruz, 2001). Para as análises biométricas (análise de variância, correlações genotípicas e índices de seleção) utilizou-se o aplicativo computacional "GENES" da Universidade de Viçosa (Cruz e Regazzi, 1994; Cruz, 2001). Para os procedimentos de contrastes ortogonais utilizou-se o aplicativo computacional "MSTATC" da Universidade de Michigan.

\section{RESULTADOS E DISCUSSÃO}

A produção total de frutos (PT) variou de 65,15 t/ha ('Hypeel 108') a
124,31 t/ha ('TEH-06') (Tabela 1). Os híbridos experimentais 'TEH-01', 'TEH-03', 'TEH-05', 'TEH-06', 'TEH09', 'ТEH-10', 'ТEH-11', 'ТEH-12', 'TEH-13', 'TEH-19', 'TEH-20', 'TEH21', 'ТEH-22', 'ТEH-25' e 'TEH-26' produziram mais de 100,00 t/ha, sendo estatisticamente superiores às duas testemunhas com relação a este parâmetro. Em termos absolutos, as combinações híbridas menos produtivas foram 'TEH02', 'TEH-07', 'RTP 1095' e 'Hypeel 108'. O híbrido 'TEH-26' atingiu o ponto de uniformidade de maturação de 94,56\% enquanto que o híbrido 'TEH13' alcançou uma uniformidade de maturação de 79,94\%. O genótipo 'Hypeel 108' expressou os maiores valores de ${ }^{\circ} \mathrm{B}$, contudo não foi estatisticamente diferente dos híbridos experimentais 'TEH-01', 'TEH-02', 'TEH-04', 'TEH-09', 'TEH-17' e 'TEH-23'. Em relação ao rendimento de pasta (um fator que combina ${ }^{\circ} \mathrm{B}$ e produção), destacaram-se os híbridos 'TEH-01', 'TEH03', 'ТEH-06', 'ТЕH-09', 'ТЕH-13', 'TEH-19', 'TEH-21', 'TEH-22', 'TEH23' e 'TEH-26'. Dentre os híbridos experimentais, para o caráter cor do fruto, dois grupos foram formados: o grupo superior formado por 15 híbridos com notas médias variando entre 3,33 e 4,00 e o inferior composto por 11 híbridos variando suas notas médias de 2,67 a 3,00 . Não se observou diferenças significativas entre as médias para o caracter firmeza de fruto.

Foram observadas diferenças estatísticas significativas, entre os híbridos experimentais, para todas as características avaliadas, exceto para PT (Tabela 2). Os híbridos utilizados como testemunhas apresentaram diferença significativa entre si somente para ${ }^{\circ} \mathrm{B}$. As interações entre híbridos experimentais e híbridos comerciais foram significativas para FM, FV, PT, ${ }^{\circ} \mathrm{B}$ e RP e não significativas para UM, CF e FF. Por meio destas interações, os híbridos experimentais foram superiores aos comerciais para FM, FV, PT e RP e inferiores em relação ao ${ }^{\circ} \mathrm{B}$ (Tabela 2 ).

Observou-se para o caráter FM alta correlação genotípica com PT $(0,93)$, UM $(0,70)$ e RP $(0,74)$ (Tabela 3$)$. Estes resultados eram esperados, uma vez que FM é um dos componentes do cálculo 
Tabela 1. Médias gerais dos híbridos experimentais e comerciais (testemunhas) em relação aos parâmetros agronômicos e industriais. Coopercentro, Cristalina (GO), 2001.

\begin{tabular}{|c|c|c|c|c|c|c|c|c|}
\hline Híbridos & $\begin{array}{c}\text { Frutos } \\
\text { maduros (t/ha) }\end{array}$ & $\begin{array}{c}\text { Frutos } \\
\text { verdes (t/ha) }\end{array}$ & $\begin{array}{l}\text { Produção } \\
\text { total (t/ha) }\end{array}$ & $\begin{array}{c}\text { Uniformidade } \\
\text { de maturação } \\
(\%)\end{array}$ & ${ }^{\circ}$ Brix & $\begin{array}{l}\text { Rendimento } \\
\text { de pasta } \\
\text { (t/ha) }\end{array}$ & Cor do fruto ${ }^{1 /}$ & $\begin{array}{c}\text { Firmeza do } \\
\text { fruto }^{2 /}\end{array}$ \\
\hline TEH-01 & $101,42 a^{2}$ & $11,12 b$ & $112,54 \mathrm{a}$ & 90,21 a & $5,11 \mathrm{a}$ & $17,40 \mathrm{a}$ & $2,67 \mathrm{~b}$ & $3,33 a$ \\
\hline TEH-02 & $62,30 \mathrm{~b}$ & $13,14 \mathrm{~b}$ & $75,44 \mathrm{~b}$ & $83,71 \mathrm{~b}$ & $5,60 \mathrm{a}$ & $11,71 \mathrm{~b}$ & $3,00 \mathrm{~b}$ & $3,33 a$ \\
\hline TEH-03 & 100,06 a & 20,39 a & 120,45 a & $83,71 \mathrm{~b}$ & $4,92 \mathrm{~b}$ & $16,51 \mathrm{a}$ & 3,33 a & $2,33 a$ \\
\hline TEH-04 & $81,25 \mathrm{~b}$ & 16,35 a & $97,60 \mathrm{~b}$ & $83,91 \mathrm{~b}$ & $5,30 \mathrm{a}$ & $14,45 \mathrm{~b}$ & $3,67 \mathrm{a}$ & $3,00 \mathrm{a}$ \\
\hline TEH-05 & 94,33 a & $21,03 a$ & 115,36 a & $81,83 b$ & $4,46 \mathrm{~b}$ & $14,13 \mathrm{~b}$ & $3,00 \mathrm{~b}$ & $3,33 a$ \\
\hline TEH-06 & $105,53 \mathrm{a}$ & 18,79 a & $124,31 \mathrm{a}$ & $84,98 \mathrm{~b}$ & $4,20 \mathrm{~b}$ & $14,87 \mathrm{a}$ & $3,00 \mathrm{~b}$ & $3,00 \mathrm{a}$ \\
\hline TEH-07 & $69,32 \mathrm{~b}$ & $9,87 \mathrm{~b}$ & $79,19 \mathrm{~b}$ & 87,90 a & 4,47 b & $10,41 \mathrm{~b}$ & $2,67 \mathrm{~b}$ & $3,00 \mathrm{a}$ \\
\hline TEH-08 & $85,72 \mathrm{a}$ & $14,21 \mathrm{~b}$ & $99,92 \mathrm{~b}$ & $85,91 \mathrm{~b}$ & $4,35 \mathrm{~b}$ & $12,53 \mathrm{~b}$ & 3,33 a & $3,33 \mathrm{a}$ \\
\hline TEH-09 & $83,40 \mathrm{~b}$ & 19,74 a & $103,14 \mathrm{a}$ & $81,93 \mathrm{~b}$ & $5,90 \mathrm{a}$ & $16,52 \mathrm{a}$ & $3,00 \mathrm{~b}$ & $4,00 \mathrm{a}$ \\
\hline TEH-10 & 90,76 a & $13,37 \mathrm{~b}$ & 104,13 a & 87,40 a & $4,52 \mathrm{~b}$ & $13,76 \mathrm{~b}$ & 3,67 a & $3,67 \mathrm{a}$ \\
\hline TEH-11 & $92,90 \mathrm{a}$ & $19,15 \mathrm{a}$ & $112,05 \mathrm{a}$ & $83,61 \mathrm{~b}$ & $4,39 \mathrm{~b}$ & $13,70 \mathrm{~b}$ & $3,00 \mathrm{~b}$ & $3,00 \mathrm{a}$ \\
\hline TEH-12 & 96,43 a & 19,05 a & 115,48 a & $84,35 \mathrm{~b}$ & $3,99 \mathrm{~b}$ & $12,91 \mathrm{~b}$ & $4,00 \mathrm{a}$ & $4,00 \mathrm{a}$ \\
\hline TEH-13 & 90,27 a & 23,19 a & 113,45 a & $79,94 \mathrm{~b}$ & $4,89 \mathrm{~b}$ & $14,82 \mathrm{a}$ & $3,00 \mathrm{~b}$ & $4,00 \mathrm{a}$ \\
\hline TEH-14 & 91,63 a & $6,39 \mathrm{~b}$ & $98,02 \mathrm{~b}$ & 93,45 a & $4,51 \mathrm{~b}$ & $13,89 \mathrm{~b}$ & $3,67 a$ & $3,00 \mathrm{a}$ \\
\hline TEH-15 & $84,11 \mathrm{~b}$ & $13,69 \mathrm{~b}$ & $97,80 \mathrm{~b}$ & $86,24 \mathrm{~b}$ & $4,62 \mathrm{~b}$ & $13,04 \mathrm{~b}$ & 3,67 a & $3,33 a$ \\
\hline TEH-16 & $75,07 \mathrm{~b}$ & $9,72 \mathrm{~b}$ & $84,79 \mathrm{~b}$ & 90,34 a & $4,34 \mathrm{~b}$ & $10,95 \mathrm{~b}$ & $2,00 \mathrm{~b}$ & $2,00 \mathrm{a}$ \\
\hline TEH-17 & $75,23 \mathrm{~b}$ & $10,77 \mathrm{~b}$ & $85,99 \mathrm{~b}$ & 87,77 a & $5,02 \mathrm{a}$ & $12,69 \mathrm{~b}$ & $3,67 a$ & $3,67 \mathrm{a}$ \\
\hline TEH-18 & 88,36 a & $12,51 \mathrm{~b}$ & $100,86 \mathrm{~b}$ & 87,87 a & $4,64 \mathrm{~b}$ & $13,75 \mathrm{~b}$ & $3,00 \mathrm{~b}$ & $3,33 a$ \\
\hline TEH-19 & 93,69 a & 20,83 a & 114,52 a & $81,96 \mathrm{~b}$ & $4,94 \mathrm{~b}$ & $15,53 \mathrm{a}$ & $3,00 \mathrm{~b}$ & 3,67 a \\
\hline TEH-20 & 93,96 a & 22,26 a & $116,22 a$ & 81,62 b & $4,47 \mathrm{~b}$ & $14,11 \mathrm{~b}$ & $3,67 a$ & $3,67 a$ \\
\hline TEH-21 & 108,70 a & $10,43 \mathrm{~b}$ & 119,13 a & 91,49 a & $4,37 \mathrm{~b}$ & $15,95 \mathrm{a}$ & $4,00 \mathrm{a}$ & $3,00 \mathrm{a}$ \\
\hline TEH-22 & $109,04 a$ & $13,64 \mathrm{~b}$ & 122,68 a & 89,70 a & $4,72 \mathrm{~b}$ & 17,26 a & 3,67 a & $3,67 a$ \\
\hline TEH-23 & 86,85 a & $6,88 \mathrm{~b}$ & $93,73 \mathrm{~b}$ & $92,90 \mathrm{a}$ & $5,28 \mathrm{a}$ & $15,39 a$ & $3,33 a$ & $3,33 a$ \\
\hline TEH-24 & $81,78 \mathrm{~b}$ & $15,51 \mathrm{a}$ & $97,28 \mathrm{~b}$ & $84,32 \mathrm{~b}$ & $4,88 \mathrm{~b}$ & $13,39 \mathrm{~b}$ & 3,33 a & $3,67 \mathrm{a}$ \\
\hline TEH-25 & $103,29 a$ & $8,75 \mathrm{~b}$ & $112,04 \mathrm{a}$ & 92,03 a & $3,98 \mathrm{~b}$ & $13,80 \mathrm{~b}$ & 3,33 a & $3,00 \mathrm{a}$ \\
\hline TEH-26 & $107,50 \mathrm{a}$ & $6,08 \mathrm{~b}$ & $113,58 \mathrm{a}$ & 94,56 a & $4,66 \mathrm{~b}$ & $16,80 \mathrm{a}$ & $4,00 \mathrm{a}$ & $3,33 \mathrm{a}$ \\
\hline RPT 1095 & $67,66 \mathrm{~b}$ & $10,37 \mathrm{~b}$ & $78,03 \mathrm{~b}$ & 86,76 b & $4,88 \mathrm{~b}$ & $11,09 \mathrm{~b}$ & 3,33 a & $3,33 a$ \\
\hline Hypeel 108 & $58,56 \mathrm{~b}$ & $6,59 \mathrm{~b}$ & $65,15 \mathrm{~b}$ & 90,00 a & $5,99 \mathrm{a}$ & $11,79 \mathrm{~b}$ & $3,00 \mathrm{~b}$ & $3,00 \mathrm{a}$ \\
\hline CV \% & 15,29 & 36,98 & 17,78 & 5,20 & 10,00 & 14,95 & 17,26 & 14,97 \\
\hline CVgenético \% & 10,19 & 24,07 & 8,05 & 3,07 & 7,90 & 9,29 & 11,53 & 10,19 \\
\hline
\end{tabular}

${ }^{1 / C o r ~ d o ~ f r u t o: ~ N o t a s ~ d e ~ 1-5 ~ o n d e ~} 1=$ fruto descolorido; $5=$ fruto vermelho intenso

${ }^{2}$ Firmeza do fruto: Notas de $1-5$ onde $1=$ fruto muito mole; $5=$ fruto muito firme

Tabela 2. Médias dos grupos de híbridos experimentais e comerciais (testemunhas), valores de $\mathrm{F}$ da análise de variância do experimento e dos contrastes entre as médias destes dois grupos. Cristalina (GO), Coopercentro, 2001.

\begin{tabular}{|c|c|c|c|c|c|}
\hline \multirow{2}{*}{ Variáveis $^{1 /}$} & \multicolumn{2}{|c|}{ Média } & \multicolumn{3}{|c|}{ Valores de F } \\
\hline & Híbridos & Testemunhas & Híbridos (H) & Testemunhas (T) & Contraste $\mathrm{H} \times \mathrm{T}$ \\
\hline Frutos maduros (t/ha) & 90,50 & 63,12 & 2,39 * * & $0,68^{\text {ns }}$ & $22,78^{* *}$ \\
\hline Frutos verdes (t/ha) & 14,49 & 8,48 & $1,84^{*}$ & 0,49 ns & $4,62^{*}$ \\
\hline Produção total (t/ha) & 104,98 & 71,59 & $1,64^{\mathrm{ns}}$ & $0,75^{n s}$ & $18,67^{* *}$ \\
\hline Uniformidade maturação (\%) & 86,68 & 88,38 & $2,52^{* *}$ & 0,77 ns & $0,79 \mathrm{~ns}$ \\
\hline${ }^{\circ}$ Brix & 4,71 & 5,44 & $2,83^{* *}$ & $8,14^{* *}$ & $12,93^{* *}$ \\
\hline Rendimento de pasta (t/ha) & 14,24 & 11,24 & 2,19 * * & $0,16 \mathrm{~ns}$ & $9,48^{* *}$ \\
\hline Cor do fruto ${ }^{1 /}$ & 3,29 & 3,17 & $2,79 * *$ & $0,69 \mathrm{~ns}$ & $0,59 \mathrm{~ns}$ \\
\hline Firmeza do fruto ${ }^{2 /}$ & 3,31 & 3,17 & $2,05^{*}$ & $0,51 \mathrm{~ns}$ & 0,34 ns \\
\hline
\end{tabular}

${ }^{\text {ns }}$ não significativo; * significativo a $5 \%$; ** significativo a $1 \%$.

${ }^{1 /}$ Cor do fruto: Notas de $1-5$ onde $1=$ fruto descolorido; $5=$ fruto vermelho intenso

${ }^{2 /}$ Firmeza do fruto: Notas de 1-5 onde $1=$ fruto muito mole; $5=$ fruto muito firme 
Tabela 3. Correlações genotípicas entre caracteres agronômicos e industriais avaliados e suas respectivas significâncias pelo Teste t de Student. Cristalina, Coopercentro, 2001.

\begin{tabular}{ccccccc|c}
\hline $\mathbf{F V}^{11}$ & $\mathbf{P T}$ & $\mathbf{U M}$ & ${ }^{\circ} \mathbf{B}$ & $\mathbf{R P}$ & $\mathbf{C F}$ & $\mathbf{F F}$ & \\
\hline$-0,40^{* *}$ & $0,93^{* *}$ & $0,70^{*}$ & $-0,48^{* *}$ & $0,74^{* *}$ & $0,65^{*}$ & $-0,09^{\mathrm{ns}}$ & $\mathbf{F M}$ \\
& $-0,24^{*}$ & $-0,95^{* *}$ & $0,47^{*}$ & $-0,10^{\mathrm{ns}}$ & $-0,07 \mathrm{~ns}$ & $0,68^{*}$ & $\mathbf{F V}$ \\
& & $0,38^{*}$ & $-0,33^{*}$ & $0,76^{* *}$ & $0,68^{*}$ & $0,19^{\mathrm{ns}}$ & $\mathbf{P T}$ \\
& & $-0,59^{*}$ & $0,34 \mathrm{~ns}$ & $0,23 \mathrm{~ns}$ & $-0,61^{*}$ & $\mathbf{U M}$ \\
& & & $0,25 \mathrm{~ns}$ & $-0,27^{*}$ & $0,31^{*}$ & ${ }^{\circ} \mathrm{B}$ \\
& & & & $0,40 \mathrm{~ns}$ & $0,07^{\mathrm{ns}}$ & $\mathbf{R P}$ \\
& & & & & $0,56^{*}$ & $\mathbf{C F}$ \\
\hline
\end{tabular}

${ }^{\mathrm{ns}}$ não significativo; * significante a 5\%; ** significante a $1 \%$.

${ }^{1 /} \mathrm{FM}=$ frutos maduros, $\mathrm{FV}=$ frutos verdes, $\mathrm{PT}=$ produção total, $\mathrm{UM}=$ uniformidade de maturação, ${ }^{\circ} \mathrm{B}=$ brix, $\mathrm{RP}=$ rendimento de pasta, $\mathrm{FF}=$ firmeza do fruto e $\mathrm{CF}=$ cor do fruto.

Tabela 4. Híbridos de melhor desempenho no experimento, de acordo com três diferentes índices de seleção de genótipos. Cristalina, Coopercentro, 2001.

\begin{tabular}{ll}
\hline Índice de seleção & \multicolumn{1}{c}{${\text { Híbridos selecionados }{ }^{1 /}}^{-}$} \\
\hline Clássico & TEH-01, TEH-03, TEH-14, TEH-21, TEH-22, TEH-23, TEH-25, \\
Multiplicativo & TEH-26, TEH-06 e TEH-10 \\
& TEH-01, TEH-03, TEH-14, TEH-21, TEH-22, TEH-23, TEH-25, \\
Genótipo-ldeotipo & TEH-26, TEH-09 e TEH-19 \\
& TEH-01, TEH-03, TEH-14, TEH-21, TEH-22, TEH-23, TEH-25, \\
& TEH-26, TEH-10 e TEH-18 \\
\hline
\end{tabular}

${ }^{1 /}$ Híbridos selecionados simultaneamente pelos três índices estão em itálico.

destas três variáveis. Os híbridos mais produtivos apresentaram menor percentual de frutos imaturos, o que pode ser confirmado pela correlação negativa entre FV e PT $(-0,24)$. Em parte, a correlação de -0,40 entre FV e FM também explica a elevada correlação genotípica inversa entre FV e UM (-0,95). A uniformidade de maturação (UM) foi inversamente relacionada com ${ }^{\circ} \mathrm{B}(-0,59)$ e FF $(-0,61)$. Em termos práticos, isto significa que genótipos mais precoces tendem a ter frutos mais moles e com teores de sólidos solúveis mais baixos, observandose uma correlação genotípica positiva entre ${ }^{\circ} \mathrm{B}$ e FF $(0,31)$. Por outro lado, a variável ${ }^{\circ} \mathrm{B}$ foi negativamente correlacionada com PT (-0.33). Os valores de correlação genotípica entre o caráter $\mathrm{CF}$ e as características FM $(0,65)$, PT $(0,68)$ e FF $(0,56)$ foram bastante interessantes nos aspectos agroindustriais. Observou-se considerável correlação direta de FF com FV $(0,68)$ e inversa com UM $(-0,61)$ indicando que quanto maior a produção de frutos maduros (FM) menos firmes serão os frutos produzidos. Entretanto, não foi observada correlação entre FM e FF $(-0,09)$ (Tabela 3$)$, indicando os efeitos de seleção das linhagens para a presen- ça simultânea de frutos firmes quando maduros.

Os índices de seleção mostraram que os híbridos: 'TEH-01', 'TEH-03', 'TEH-14', 'TEH-21', 'TEH-22', 'TEH23', 'TEH-25' e 'TEH-26', apresentaram os melhores desempenhos no experimento, sendo selecionados simultaneamente pelos três índices. Adicionalmente, o índice Clássico permitiu selecionar 'TEH-06' e 'TEH-10', o Multiplicativo 'TEH-09' e 'TEH-19' e o Genótipo-Ideótipo ‘TEH-10' e 'TEH18' (Tabela 4).

As linhagens 'CNPH 1278', 'CNPH 1299', 'CNPH 1306' e 'CNPH 1346' se destacaram como as que mais figuram como parentais dentre os híbridos selecionados. Contrastes ortogonais entre o grupo de híbridos experimentais provenientes de uma destas linhagens e o grupo formado pelos demais híbridos mostraram que os híbridos derivados da linhagem 'CNPH 1278' foram inferiores aos demais em relação a FV, UM, ${ }^{\circ} \mathrm{B}$ e RP. O grupo de híbridos oriundos da linha 'CNPH 1306' foi superiores aos demais em relação ao ${ }^{\circ} \mathrm{B}$, e inferior quanto a FM e PT. Os híbridos formados a partir da linhagem 'CNPH 1346' foram superiores aos demais no que diz respeito a ${ }^{\circ} \mathrm{B}$ e RP. A linhagem ' $\mathrm{CNPH}$ 1299’ apresentou o melhor desempenho, sendo que o grupo formado por seus híbridos foi superior aos demais nas características FM, FV, UM, RP e FF (Tabela 5).

As análises dos contrastes ortogonais entre os híbridos comerciais e o grupo formado por todos os híbridos experimentais mostraram que apesar deles terem apresentado menores

Tabela 5. Valores dos contrastes ortogonais (teste F) entre o grupo de híbridos experimentais de um determinado genitor e o grupo dos demais híbridos do ensaio e entre cada híbrido comercial com o grupo formado pelos híbridos experimentais. Cristalina, Coopercentro, 2001

\begin{tabular}{|c|c|c|c|c|c|c|c|c|}
\hline Genótipo avaliado & $\mathrm{FM}^{1 /}$ & $\mathrm{FV}$ & PT & UM & ${ }^{\circ} \mathrm{B}$ & RP & FF & CF \\
\hline CNPH 1278 & 6,38 ns & 3,78 * & 10,16 ns & $-2,37^{*}$ & $-0,57^{* *}$ & $-19,33$ * & 0,07 ns & $0,11^{\text {ns }}$ \\
\hline CNPH 1299 & $10,87^{*}$ & $-5,48$ ** & $5,38^{\text {ns }}$ & 5,46 ** & $0,05^{\mathrm{ns}}$ & 57,14 ** & 0,54 ** & 0,12 ns \\
\hline CNPH 1306 & $-6,19$ * & $-0,02 \mathrm{~ns}$ & $-6,20$ * & $-0,83^{n s}$ & 0,20 * & $-12,35^{n s}$ & $-0,25^{*}$ & $-0,08^{\text {ns }}$ \\
\hline CNPH 1346 & 2,55 ns & 2,05 ns & 4,60 ns & $-1,33$ ns & 0,29 ** & 41,99 * & 0,07 ns & $0,05^{\mathrm{ns}}$ \\
\hline RTP 1095 & $-22,83$ ** & $-4,13^{\mathrm{ns}}$ & $-26,96$ * & 0,09 ns & $0,17^{\text {ns }}$ & $-3,15$ * & $0,044^{\text {ns }}$ & $0,03^{n s}$ \\
\hline Hypeel 108 & $-31,93$ ** & $-7,91^{*}$ & $-39,84 * *$ & 3,32 ns & 1,28 ** & $-2,45^{n s}$ & $-0,29 \mathrm{~ns}$ & $-0,31^{\mathrm{ns}}$ \\
\hline
\end{tabular}

${ }^{\text {ns }}$ não significativo; $*$ significante a $5 \% ; * *$ significante a $1 \%$.

${ }^{1 /} \mathrm{FM}=$ frutos maduros, $\mathrm{FV}=$ frutos verdes, $\mathrm{PT}=$ produção total, $\mathrm{UM}=$ uniformidade de maturação, ${ }^{\circ} \mathrm{B}=$ brix, $\mathrm{RP}=$ rendimento de pasta, $\mathrm{FF}$ = firmeza do fruto e $\mathrm{CF}=$ cor do fruto. 
valores na variável $\mathrm{FV}$, foram muito insatisfatórios quanto às características FM e PT, principalmente o híbrido comercial 'Hypeel 108' (Tabela 1 e 5). Para o 'RTP 1095', este desempenho foi pior devido ao fato de apresentar também valores baixos de RP. Por outro lado, 'Hypeel 108' apresentou a maior média de ${ }^{\circ} \mathrm{B}$ de todo o experimento (Tabela 1 ).

Deste modo, o grupo dos híbridos obtidos a partir das linhagens 'CNPH 1299' e 'CNPH 1346' foram os que apresentaram melhor desempenho para um maior número de características de interesse avaliadas no experimento. Desta forma, seria interessante avaliar um híbrido específico do cruzamento entre estas duas linhagens cujos contrastes indicam uma combinação bastante promissora. Conclui-se que este conjunto de híbridos experimentais, oriundos do programa de melhoramento da Embrapa Hortaliças, apresenta genótipos promissores para cultivo nas condições de cerrado. Além disso, as in- formações obtidas por meio da avaliação deste conjunto de híbridos serão ferramentas importante na seleção de novos genótipos superiores.

\section{AGRADECIMENTOS}

Os autores do presente trabalho agradecem à Coopercentro (Cristalina, GO) pelo auxílio na instalação, condução e colheita do experimento, e ao Dr. Valter Rodrigues de Oliveira pela revisão do texto.

\section{LITERATURA CITADA}

BARBOSA, V. The processing tomato growing system under tropical and subtropical conditions: the Brazilian experience. In: $1 \mathrm{ST}$. INT'L CONFERENCE ON PROCESSING TOMATO AND 1ST. INT'L SYMPOSIUM ON TROPICAL TOMATO DISEASES, 1996, Recife, PE. Proceedings of 1 st. Int' 1 conference on the processing tomato and 1st. Int 1 symposium on tropical tomato diseases. 1997. p.94-97.
CRUZ, C.D. Genes: programa para análise e processamento de dados baseado em modelos de genética e estatística experimental. Viçosa: UFV, 2001. 441 p.

CRUZ, C.D.; REGAZZI, A.J. Modelos Biométricos Aplicados ao Melhoramento Genético. 1.ed. Viçosa: UFV, 1994. 390 p.

GOMES, F.P. Curso de Estatística Experimental. 14.ed. Piracicaba: ESALQ, 2000. 477 p.

HAZEL, L.N. The genetic basis for constructing selection indexes. Genetics, Austin, v.28, p.476490, 1943.

MELO, P.C.T.; VILELA, N.J. Desempenho da cadeia agroindustrial brasileira do tomate na década de 90. Horticultura Brasileira, Brasília, v.22, n.1, p. 154-160, 2004.

SILVA, J.B.C.; GIORDANO, L.B. Produção mundial e nacional. In: SILVA, J.B.C. \& GIORDANO, L.B., org. Tomate para processamento industrial. Brasília: Embrapa Comunicação para Transferência de Tecnologia / Embrapa Hortaliças, 2000. p.811.

SMITH, H.F. A discriminant function for plant selection. Ann. Eugen., v.7, p.240-250, 1936. SUBANDI, W.; COMPTON, A.; EMPIG, L.T. Comparison of the efficiences of selection indices for three traits in two variety crosses of corn. Crop Science. , v.13, p.184-186, 1973. 